\title{
Association of Angiotensin II-Stimulating Antihypertensive Use and Dementia Risk
}

\author{
Post Hoc Analysis of the PreDIVA Trial
}

\author{
Jan Willem van Dalen, PhD, * Zachary A. Marcum, PharmD, PhD, * Shelly L. Gray, PharmD, MS, \\ Douglas Barthold, PhD, Eric P. Moll van Charante, MD, PhD, Willem A. van Gool, MD, PhD, \\ Paul K. Crane, MD, MPH, Eric B. Larson, MD, MPH, and Edo Richard, MD, PhD
}

Neurology ${ }^{\circledR}$ 2021;96:e67-e80. doi:10.1212/WNL.0000000000010996

\section{Abstract}

\section{Objective}

To assess whether angiotensin II-stimulating antihypertensives (thiazides, dihydropyridine calcium channel blockers, and angiotensin I receptor blockers) convey a lower risk of incident dementia compared to angiotensin II-inhibiting antihypertensives (angiotensin-converting enzyme inhibitors, $\beta$-blockers, and nondihydropyridine calcium channel blockers), in accordance with the "angiotensin hypothesis."

\section{Methods}

We performed Cox regression analyses of incident dementia (or mortality as competing risk) during 6-8 years of follow-up in a population sample of 1,909 community-dwelling individuals (54\% women) without dementia, aged 70-78 (mean $74.5 \pm 2.5$ ) years.

\section{Results}

After a median of 6.7 years of follow-up, dementia status was available for 1,870 (98\%) and mortality for 1,904 (>99\%) participants. Dementia incidence was 5.6\% (27/480) in angiotensin II-stimulating, 8.2\% (59/721) in angiotensin II-inhibiting, and 6.9\% (46/669) in both antihypertensive type users. Adjusted for dementia risk factors including blood pressure and medical history, angiotensin II-stimulating antihypertensive users had a $45 \%$ lower incident dementia rate (hazard ratio [HR], 0.55; 95\% CI, 0.34-0.89) without excess mortality (HR, 0.86; 95\% CI, 0.64-1.16), and individuals using both types had a nonsignificant $20 \%$ lower dementia rate (HR, 0.80; 95\% CI,0.53-1.20) without excess mortality (HR, 0.97; 95\% CI, 0.76-1.24), compared to angiotensin II-inhibiting antihypertensive users. Results were consistent for subgroups based on diabetes and stroke history, but may be specific for individuals without a history of cardiovascular disease.

\section{Conclusions}

Users of angiotensin II-stimulating antihypertensives had lower dementia rates compared to angiotensin II-inhibiting antihypertensive users, supporting the angiotensin hypothesis. Confounding by indication must be examined further, although subanalyses suggest this did not influence results. If replicated, dementia prevention could become a compelling indication for older individuals receiving antihypertensive treatment.

\author{
Correspondence \\ Dr. van Dalen \\ j.vandalen@amc.nl
}

\section{MORE ONLINE}

- CME Course

NPub.org/cmelist

\footnotetext{
*These authors contributed equally to this work.

From the Departments of Neurology (J.W.v.D., W.A.v.G., E.R.) and General Practice (E.P.M.v.C.), Amsterdam UMC, University of Amsterdam; Department of Neurology (J.W.v.D., E.R.), Donders Institute for Brain, Behaviour and Cognition, Radboud University Medical Centre, Nijmegen, the Netherlands; Schools of Pharmacy (Z.A.M., S.L.G., D.B.) and Medicine (P.K.C.), University of Washington; and Kaiser Permanente Washington Health Research Institute (E.B.L.), Seattle.

Go to Neurology.org/N for full disclosures. Funding information and disclosures deemed relevant by the authors, if any, are provided at the end of the article. The Article Processing Charge was funded by University of Amsterdam.

This is an open access article distributed under the terms of the Creative Commons Attribution-NonCommercial-NoDerivatives License 4.0 (CC BY-NC-ND), which permits downloading and sharing the work provided it is properly cited. The work cannot be changed in any way or used commercially without permission from the journal.
} 


\section{Glossary}

$\mathbf{A} \beta=\beta$-amyloid $\mathbf{A C E}=$ angiotensin-converting enzyme; $\mathbf{A C E I}=$ angiotensin-converting enzyme inhibitor $\mathbf{A R B}=$ angiotensin receptor blocker; $\mathbf{A R R}=$ absolute risk reduction; $\mathbf{A T}=$ angiotensin type; $\mathbf{B B}=\beta$-blocker; $\mathbf{B M I}=$ body mass index; $\mathbf{B P}=$ blood pressure; $\mathbf{C C B}=$ calcium channel blocker; $\mathbf{C I}=$ confidence interval; $\mathbf{C V D}=$ cardiovascular disease; $\mathbf{D i C C B}=$ dihydropyridine calcium channel blocker; DM = diabetes mellitus; DSM-IV = Diagnostic and Statistical Manual of Mental Disorders, 4th edition; HR = hazard ratio; MMSE = Mini-Mental State Examination; PreDIVA $=$ Prevention of Dementia by Intensive Vascular Care; RAS = renin-angiotensin system; RCT = randomized controlled trial.

Midlife hypertension is associated with an increased risk of incident dementia. ${ }^{1,2}$ Studies on blood pressure (BP) lowering in older people, however, show mixed effects on dementia risk. ${ }^{1,3-5}$ Accumulating evidence suggests that some antihypertensive drug subclasses may reduce incident dementia beyond their effect on BP. ${ }^{6}$ Subclasses most consistently associated with reduced dementia risk compared to other antihypertensives are angiotensin receptor blockers, certain calcium channel blockers, and diuretics. ${ }^{6-14}$

The mechanisms underlying these differential effects are unclear. $^{6-12,15}$ They may be related to the renin-angiotensin system (RAS; figure 1). ${ }^{16,17}$ In the RAS, angiotensin II lowers $\mathrm{BP}$, mainly via activity at angiotensin type 1 (AT1) receptors. ${ }^{18-20}$ It also activates AT2 receptors and AT4 receptors, ${ }^{18-20}$ which have a number of associated effects (vasodilation, apoptosis). ${ }^{18-20}$ Hypothetically, the RAS also helps maintain brain function. Angiotensin II and IV seem to protect against ischemia, especially through AT2, ${ }^{16,21,22}$ and preserve memory through AT4. ${ }^{23,24}$ Furthermore, angiotensin- converting enzyme mediates $\beta$-amyloid $(A \beta)$ degradation in the brain. ${ }^{16,25}$ Based on these effects, drugs that increase angiotensin II-mediated activity at the AT2 and AT4 receptors (angiotensin II-stimulating) may provide brain protection compared to those decreasing activity at these receptors (angiotensin II-inhibiting). This angiotensin hypothesis (figure 1) is supported by both experimental and human studies. ${ }^{16}$ However, little empirical evidence exists evaluating the hypothesis in a single, well-delineated population.

We investigated whether, in line with the angiotensin hypothesis, angiotensin II-stimulating antihypertensive use conveyed a lower risk of incident dementia compared to angiotensin II-inhibiting antihypertensive use, independently of BP levels, in a large cohort of community-dwelling older people.

\section{Methods}

\section{Participants and Study Design}

Data were derived from the Prevention of Dementia by Intensive Vascular Care (PreDIVA) trial (registration: ISRCTN29711771). ${ }^{26}$ This randomized controlled trial (RCT) tested the efficacy of 4-monthly visits to a practice nurse for cardiovascular risk management, compared to usual care by the general practitioner, on the prevention of dementia. ${ }^{26}$
Community-dwelling individuals aged $70-78$ years registered with a participating general practice ( $>98 \%$ of the Dutch population is registered) were invited to participate (figure e-1, available from Dryad; doi.org/10.5061/dryad.hdr7sqvfd). Exclusion criteria were dementia and disorders likely to hinder long-term follow-up (e.g., terminal illness, alcoholism). Recruitment was from June 7, 2006, until March 12, 2009. Participants were assessed at baseline and biennial follow-up assessments. At these visits, data were collected on medical history, lifestyle, and medication, using patients' self-report cross-checked with electronic health records. A full description per variable is given in Methods e-1 (available from Dryad; doi. org/10.5061/dryad.hdr7sqvfd). Measurements included cardiovascular risk factors, cognitive status (Mini-Mental State Examination and Visual Association Test), depression, and disability. Blood laboratory measures and APOE $\varepsilon 4$ genotype were also obtained. The final assessment took place March 4, 2015, with follow-up ranging 6-8 years. Because the PreDIVA intervention did not dictate or influence the antihypertensive classes prescribed, the current study analyzed the trial treatment arms as one single observational cohort. Only antihypertensive users were included because nonusers are uninformative when investigating differential antihypertensive subclass effects.

\section{Standard Protocol Approvals, Registrations, and Patient Consents}

The study was approved by the medical ethics committee of the Academic Medical Center, Amsterdam, the Netherlands. Participants gave written informed consent before their baseline visit.

\section{Antihypertensive Use}

Figure 1 depicts the different effects of antihypertensive subclasses on angiotensin II. ${ }^{18}$ Angiotensin-converting enzyme inhibitors (ACEIs) directly inhibit angiotensin II production. ${ }^{18}$ Angiotensin II receptor blockers (ARBs) block AT1 receptors, increasing AT2 and AT4 activation and raising angiotensin II levels by stimulating renin production. ${ }^{18}$ Dihydropyridine calcium channel blockers (DiCCBs) and diuretics (thiazide, $\mathrm{K}+$ sparing, and loop) also increase angiotensin II by stimulating renin release. ${ }^{18,27,28}$ Other antihypertensives mostly decrease angiotensin II via renin. $\beta$-Blockers (BBs) reduce $\beta 1$-mediated renin production. ${ }^{18}$ Long-acting forms of verapamil and diltiazem (non-DiCCBs) are either neutral or decrease renin by reducing sympathetic tone. ${ }^{29}$ Renin antagonists directly inhibit renin activity. ${ }^{18}$ 


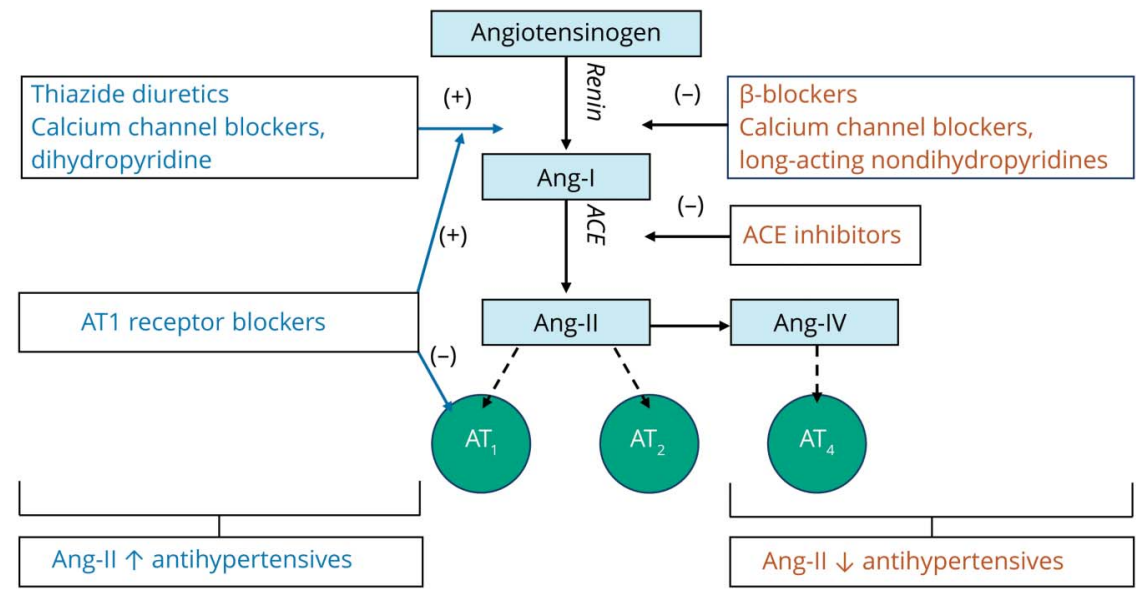

Thiazides and dihydropyridine calcium channel blockers (DiCCBs) increase renin. $\beta$-blockers (BB) reduce $\beta_{1}$-mediated renin production. Long-acting forms of verapamil and diltiazem (non-DiCCBs) either do not affect or reduce renin. Renin generates angiotensin I (Ang-I), which is converted into angiotensin II (Ang-II) by angiotensin-converting enzyme (ACE), which exerts physiologic effects by binding to $A T_{1}$ or $A T_{2}$ or may be further metabolized into Ang-IV, which binds to $\mathrm{AT}_{4}$. ACE inhibitors (ACEI) directly inhibit ACE activity, thereby inhibiting angiotensin II production. Angiotensin receptor 1 blockers (ARBs) inhibit angiotensin II activity directly at the AT1 receptor, but leave angiotensin II production intact. Angiotensin hypothesis: ACE reportedly degrades $\beta$-amyloid $(A \beta)$, a major component of the cerebral neuritic plaques associated with Alzheimer disease. ACEls may inhibit this degradation, thus facilitating $A \beta$ plaques accumulation. ARBs selectively inhibit Ang-II at angiotensin receptor $1\left(\mathrm{AT}_{1}\right)$ without inhibiting $\mathrm{ACE}$, allowing ACE to degrade AB. Moreover, Ang-II and Ang-IV activity have been associated with protection from ischemia via activity at $A T_{2}$ and possibly $A_{4}$. In addition, Ang-II and Ang-IV activity have been associated with direct effects on memory. Taken together, antihypertensives that increase activity at $\mathrm{AT}_{2}$ and $\mathrm{AT}_{4}$ (Ang-II-stimulating antihypertensives) are hypothesized to have greater brain protective effects than those that decrease activity at the same receptors (Ang-II-inhibiting antihypertensives). Blue text: Ang-II-stimulating antihypertensives; red text: Ang-II-inhibiting antihypertensives; light blue boxes: angiotensin peptides; green circles: angiotensin receptors.

Antihypertensive use was based on prescription records crosschecked with participants during the baseline assessment. Individuals using ARBs, DiCCBs, or thiazide(-like) diuretics were categorized as angiotensin II-stimulating antihypertensive users. Individuals using non-DiCCBs, BBs, and ACEIs were categorized as angiotensin II-inhibiting antihypertensive users. Participants were not categorized in either group based on K-sparing or loop diuretic use since these medications are not prescribed as first-choice medication for hypertension but generally as adjunct medication for specific comorbidity. ${ }^{30}$ Effects of excluding these antihypertensive types were tested in a sensitivity analysis.

Antihypertensives were subcategorized according to Anatomical Therapeutic Chemical codes: angiotensin II-stimulating: ARBs: C09CA, C09DA, C09DB, C09DX01, C09DX03; DiCCBs: C08CA, C08GA; thiazide diuretics: C03A, C03EA01, C03EA02, C03EA03, C03EA04, C03EA05, C03EA07, C03EA13, C03EA14; thiazide-like diuretics: C03B, C03EA6, C03EA12; angiotensin II-inhibiting: ACEIs: C09AA, C09BA, C09BB, C09BX01, C09BX02; BBs: C07A, C07B, C07C, C07D, C09BX02; non-DiCCBs: C08CX, C08D, C08E; other: loop diuretics: C03C, C03EB; K-sparing diuretics: C03D, C03E, C03BB, C03CB.

\section{Dementia}

The dementia diagnostic process has been described in detail previously, ${ }^{26}$ and is comprehensively delineated in Methods e-2 (doi.org/10.5061/dryad.hdr7sqvfd). Dementia was defined as a clinical diagnosis of all-cause dementia according to DSM-IV criteria, confirmed by 2 members of an independent outcome adjudication committee based on all available clinical information. All individuals with a clinical dementia diagnosis during the course of the study were adjudicated. In addition, individuals who had a Mini-Mental State Examination (MMSE) score $<24$ points during the course of the study or $>2$ points decline compared to baseline were referred to their general practitioner for clinical evaluation, and adjudicated by the outcome committee. Dementia diagnoses were reevaluated after 1 year of additional follow-up to avoid false-positive diagnoses. For participants who dropped out of the study, the dementia status was retrieved by a dedicated research nurse from electronic health records or contact with the general practitioner at the end of the study, and all written clinical information was presented to the adjudication committee.

\section{Statistical Analyses}

Characteristics of individuals using angiotensin II-stimulating, angiotensin II-inhibiting, and both antihypertensive types in combination (angiotensin-mixed) were compared using oneway analysis of variance and Fisher exact tests. Cox regression analyses were performed using age at diagnosis as time scale and age at baseline as time of entry. Dementia was the main outcome and angiotensin status (all categories together in one model with angiotensin II-inhibiting as reference category) was the independent variable. In these types of longitudinal analyses, competing risk of death is a major potential source of bias. ${ }^{31}$ To assess the influence of the competing risk of death, we used the 
cause-specific hazard approach, repeating all analyses with mortality and dementia/mortality combined as outcomes. ${ }^{31}$ Individuals with missing data were left out per model (i.e., pairwise). Model 1 was unadjusted. Model 2 adjusted for baseline systolic BP and history of diabetes mellitus (DM), cardiovascular disease (CVD), and stroke (including TIA) as comorbidity potentially influencing both the antihypertensive subclass prescribed and the risk of poor outcome, and education (years, continuous). ${ }^{1,30}$ Model 3 additionally adjusted for other dementia risk factors including body mass index (BMI), cholesterol-lowering medication use (as proxy for dyslipidemia), estimated glomerular filtration rate, ${ }^{1}$ and trial intervention allocation to ensure the trial intervention did not influence results. $^{26}$ The proportional hazards assumption for the Cox regression analyses was tested by visual assessment of the plotted Schoenfeld residuals. To further assess whether associations were influenced by hypertension severity and disease history (e.g., ACEI with diabetes; BB after myocardial infarction), ${ }^{30}$ we performed subgroup analyses stratified by history of DM, stroke, CVD, and tertiles of systolic BP. Significance for stratification according to these subgroups ( $p$ interaction) was tested using likelihood ratio tests comparing models with and without interaction terms for each separate subgroup variable.

In a sensitivity analysis, we included loop- and K-sparing diuretics as angiotensin II-stimulating antihypertensives, since under the angiotensin hypothesis they would most likely stimulate renin release. ${ }^{18,28}$ In explorative analyses, we repeated the main analyses for each individual antihypertensive class independently in a separate model adjusted for concomitant use of any other antihypertensive (yes/no) to assess whether these associations concur with expectations based on the angiotensin hypothesis. To compare categorization into angiotensin II-stimulating and angiotensin II-inhibiting subtypes to any random other dichotomization into antihypertensive group, we plotted hazard ratios (HRs) for each possible combination of antihypertensive subclasses adjusted using model 3. To further examine how competing risk of death would influence dementia incidence, we performed a sensitivity analysis using the Fine-Gray competing risks model. To assess whether results would be influenced by adjusting for BP measures other than systolic BP, we performed separate sensitivity analyses adjusting for diastolic $\mathrm{BP}$, mean arterial pressure, and pulse pressure. To assess whether attainment of BP control was of influence, we included a sensitivity analysis adjusted for BP control at the first visit after baseline, operationalized as a systolic BP $\leq 140 \mathrm{~mm} \mathrm{Hg}$ and a diastolic BP $\leq 90 \mathrm{~mm} \mathrm{Hg}$. Finally, to assess the potential for residual confounding fully explaining results, we calculated E-values for the point estimates in the fully adjusted analyses, using the $\mathrm{R}$ package Evalues. $^{32,33}$ The E-value answers the question how strong would the unmeasured confounding would have to be to negate the observed results. ${ }^{32}$ It quantifies the minimum strength of association on the HR scale that an unmeasured confounder must have with both the treatment and outcome, while simultaneously considering the measured covariates, to negate the observed treatment-outcome association. ${ }^{32}$
Figure 2 Study Flow Chart

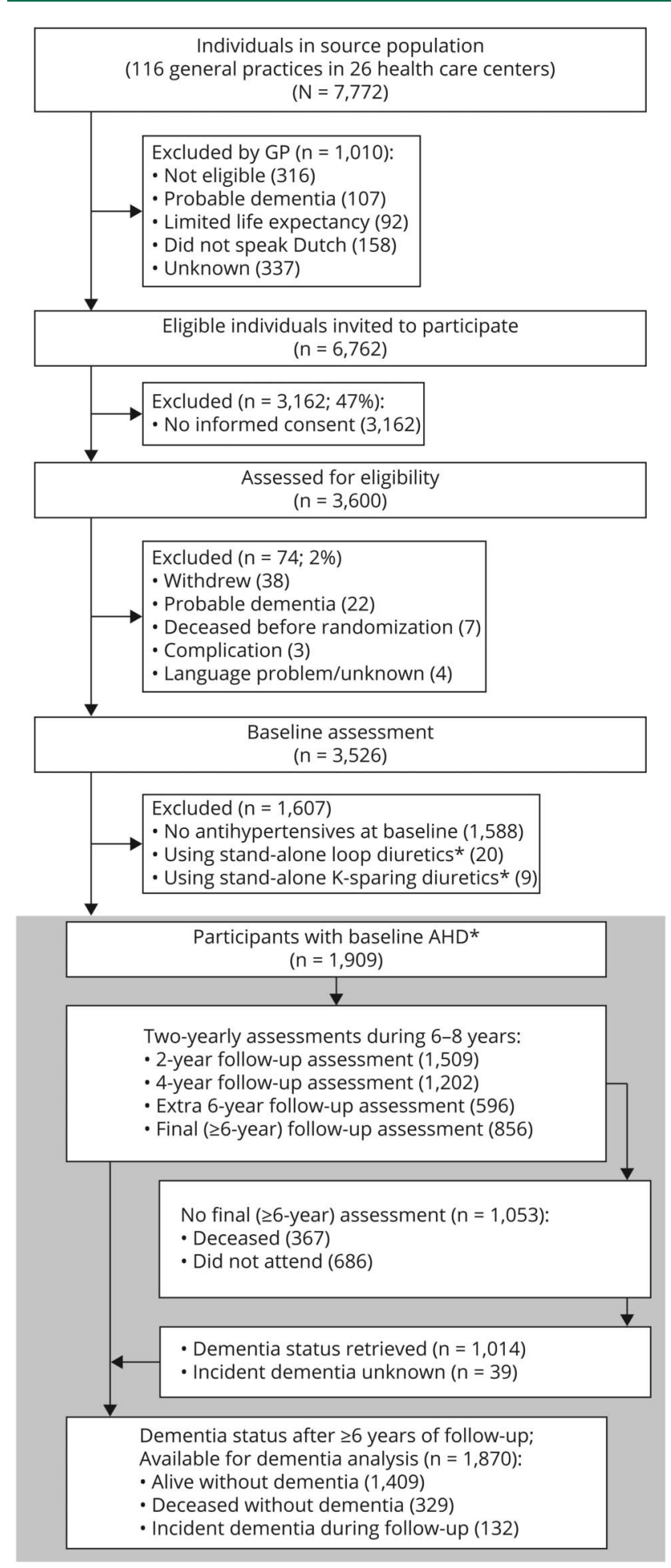

*Only individuals using antihypertensive drug (AHD) types from thiazide(-like), angiotensin 1 receptor blocker, angiotensin-converting enzyme inhibitor calcium channel blocker, and $\beta$-blocker classes were included because loop and K-sparing diuretics are generally not prescribed as stand-alone treatments for hypertension. There were no individuals using renin antagonists.

\section{Data Availability}

All data used for this study are available from the authors upon reasonable request. 
Table 1 Population Characteristics

\begin{tabular}{|c|c|c|c|c|}
\hline & Ang+ $(n=492)$ & Ang- $(n=733)$ & Ang $\pm(n=684)$ & $p$ Value \\
\hline Age, y & $74.5(2.5)$ & $74.6(2.5)$ & $74.5(2.5)$ & 0.84 \\
\hline Female & $321(65.2)$ & $340(46.4)$ & $364(53.2)$ & $<0.001$ \\
\hline Systolic BP, mm Hg & $156.6(20.5)$ & $155.0(22.1)$ & $157.9(21.3)$ & 0.04 \\
\hline Diastolic BP, mm Hg & $82.4(10.5)$ & $81.4(11.7)$ & $80.7(11.0)$ & 0.04 \\
\hline \multicolumn{5}{|l|}{ Ang+ AHD } \\
\hline Thiazide & $222(45.1)$ & & $352(51.5)$ & 0.03 \\
\hline Thiazide-like & $22(4.5)$ & & $36(5.3)$ & 0.59 \\
\hline DiCCB & $145(29.5)$ & & $262(38.3)$ & $<0.001$ \\
\hline ARB & $231(47.0)$ & & $171(25.0)$ & $<0.001$ \\
\hline \multicolumn{5}{|l|}{ Ang- AHD } \\
\hline Non-DiCCB & & 86 (11.7) & $31(4.5)$ & $<0.001$ \\
\hline ACEI & & 344 (46.9) & $289(42.3)$ & 0.08 \\
\hline BB & & $472(64.4)$ & $514(75.1)$ & $<0.001$ \\
\hline \multicolumn{5}{|l|}{$\begin{array}{l}\text { Non thiazide(-like) } \\
\text { diuretics }\end{array}$} \\
\hline Loop diuretics & $12(2.4)$ & $74(10.1)$ & $49(7.2)$ & $<0.001$ \\
\hline K-sparing diuretics & $66(13.4)$ & $33(4.5)$ & $90(13.2)$ & $<0.001$ \\
\hline BMI, kg/m² & $28.6(4.6)$ & $27.8(3.9)$ & $28.7(4.2)$ & $<0.001$ \\
\hline Diabetes & $100(20.3)$ & 175 (23.9) & 229 (33.5) & $<0.001$ \\
\hline Serum LDL, mmol/L & $3.1(1.0)$ & $2.8(0.9)$ & $2.8(1.0)$ & $<0.001$ \\
\hline Cholesterol-lowering drugs & $169(34.3)$ & $382(52.1)$ & $370(54.1)$ & $<0.001$ \\
\hline eGFR, $\mathrm{mL} / \mathrm{min}$ & $74.3(15.7)$ & $74.2(16.5)$ & $72.4(20.0)$ & 0.09 \\
\hline Stroke & $61 / 489(12.5)$ & $89 / 724(12.3)$ & $107 / 669(16.0)$ & 0.16 \\
\hline CVD & $105 / 489(21.5)$ & $384 / 727(52.8)$ & $322 / 681(47.3)$ & $<0.001$ \\
\hline APOE $\varepsilon 4$ positive & $112 / 411(27.3)$ & 166/608 (27.3) & $168 / 592(28.4)$ & 0.94 \\
\hline Education, y & $11.5(3.1)$ & $11.6(3.4)$ & $11.5(2.9)$ & 0.65 \\
\hline$<7$ & $129 / 491(26.3)$ & $185 / 729(25.4)$ & 178/676 (26.3) & 0.94 \\
\hline $7-12$ & 270/491 (55) & $394 / 729(54)$ & $393 / 676(58.1)$ & 0.70 \\
\hline$>12$ & 92/491 (18.7) & 150/729 (20.6) & $105 / 676(15.5)$ & 0.12 \\
\hline MMSE score & $28.1(1.8)$ & $27.9(1.9)$ & $28.1(1.9)$ & 0.17 \\
\hline \multicolumn{5}{|l|}{ Outcomes } \\
\hline Dementia & $27 / 480(5.6)$ & $59 / 721(8.2)$ & $46 / 669(6.9)$ & 0.28 \\
\hline Deceased & 73/491 (14.9) & $154 / 730(21.1)$ & $140 / 683(20.5)$ & 0.06 \\
\hline
\end{tabular}

Abbreviations: $\mathrm{AHD}=$ antihypertensive drug; Ang+ = individuals using angiotensin II-stimulating medication; Ang- = individuals using angiotensin II-inhibiting medication; Ang $\pm=$ individuals using both angiotensin II-stimulating and angiotensin II-inhibiting medication; $A C E I=$ angiotensin-converting enzyme inhibitor; $\mathrm{ARB}=$ angiotensin receptor blocker; $\mathrm{BB}=\beta$-blocker; $\mathrm{BMI}=$ body mass index; $\mathrm{BP}=$ blood pressure; $\mathrm{CVD}=$ cardiovascular disease; $\mathrm{DiCCB}=$ dihydropyridine calcium channel blocker; eGFR = estimated glomerular filtration rate; LDL = low-density lipoprotein; MMSE = Mini-Mental State Examination.

Values are mean (SD) or proportion (\%) per group. $p$ Values for one-way analysis of variance for means or Fisher exact tests for proportions. Missing: (Ang+/Ang-/Ang士): BMI: 0/1/0, LDL: 8/15/24, eGFR: 7/14/21, stroke: 3/9/15, CVD: 3/6/3, EduCat: 1/4/8, MMSE: 0/1/2, dementia: 12/12/15, deceased: $1 / 3 / 1$. 
Table 2 Hazard Ratios (HRs) for Individuals Using Angiotensin II-Stimulating (Ang+) or Both Ang+ and Angiotensin II-Inhibiting (Ang-) Antihypertensives Compared With Those Using Ang- Antihypertensives Only

\begin{tabular}{|c|c|c|c|c|c|c|c|c|}
\hline \multirow[b]{2}{*}{ Outcome/AHD } & \multicolumn{4}{|l|}{ Model 1} & \multicolumn{4}{|l|}{ Model 3} \\
\hline & Events/exposed & HR & $95 \% \mathrm{Cl}$ & $p$ Value & Events/exposed & HR & $95 \% \mathrm{Cl}$ & $p$ Value \\
\hline \multicolumn{9}{|c|}{ Dementia $(n=132 / 1,870)$} \\
\hline Ang- & $59 / 721$ & 1.00 & (ref) & & $57 / 689$ & 1.00 & (ref) & \\
\hline Ang+ & $27 / 480$ & 0.67 & $(0.42-1.06)$ & 0.08 & $26 / 467$ & 0.57 & $(0.35-0.93)$ & 0.02 \\
\hline Ang \pm & $46 / 669$ & 0.83 & $(0.57-1.22)$ & 0.35 & $42 / 624$ & 0.77 & $(0.51-1.15)$ & 0.20 \\
\hline \multicolumn{9}{|c|}{ Mortality ( $n=354 / 1,867$ ) } \\
\hline Ang- & $148 / 719$ & 1.00 & (ref) & & $143 / 687$ & 1.00 & (ref) & \\
\hline Ang+ & $70 / 480$ & 0.69 & $(0.52-0.92)$ & 0.01 & $69 / 467$ & 0.86 & $(0.64-1.16)$ & 0.31 \\
\hline Ang \pm & $136 / 668$ & 0.94 & $(0.78-1.24)$ & 0.86 & $126 / 623$ & 0.96 & $(0.75-1.23)$ & 0.75 \\
\hline \multicolumn{9}{|c|}{$\begin{array}{l}\text { Dementia/mortality } \\
(n=461 / 1,868)\end{array}$} \\
\hline Ang- & $196 / 720$ & 1.00 & (ref) & & $189 / 688$ & 1.00 & (ref) & \\
\hline Ang+ & $93 / 480$ & 0.69 & $(0.54-0.89)$ & 0.004 & $91 / 467$ & 0.78 & $(0.60-1.02)$ & 0.07 \\
\hline Ang \pm & $172 / 668$ & 0.98 & $(0.76-1.15)$ & 0.53 & $159 / 623$ & 0.91 & $(0.74-1.13)$ & 0.41 \\
\hline \multicolumn{9}{|c|}{$\begin{array}{l}\text { Abbreviations: AHD = antihypertensive drug; } \mathrm{Cl}=\text { confidence interval; (ref) = reference group. } \\
\text { Results of Cox proportional hazard analyses of incident dementia, mortality, or dementia/mortality. Associations for Ang+ and Ang } \pm \text { together in one model } \\
\text { with Ang- as the reference category (i.e., HR 1.00). Age at time of event was used as time scale and age at baseline as time of study entry. Model } 1: \text { adjusted for } \\
\text { sex; model 2: additionally adjusted for education, systolic blood pressure, and history of diabetes, stroke, and cardiovascular disease at baseline; model } 3 \text { : } \\
\text { additionally adjusted for body mass index, cholesterol medication use, estimated glomerular filtration rate, and trial treatment arm. Results for model } 2 \text { are } \\
\text { shown in supplement table e-1a (doi.org/10.5061/dryad.hdr7sqvfd). } \mathrm{n}=\text { Total number of events/individuals per subgroup in model } 1 \text {. Events/exposed = total } \\
\text { number of events/individuals in the angiotensin category per subgroup. }\end{array}$} \\
\hline
\end{tabular}

\section{Results}

The flow chart (figure 2) lists individuals included in and excluded from the analyses. Of the 3,526 PreDIVA participants, 1,909 (54\%) used angiotensin II-stimulating or angiotensin II-inhibiting antihypertensives at baseline and were thus included. After 6-8 years of follow-up (median 6.7 years, interquartile range 5.8-7.0), dementia outcome was available for $98 \%(1,870 / 1,909)$ and mortality for $>99 \%(1,904 / 1,909)$ of participants. In total, 132 (7\%) individuals developed dementia and 329 (17\%) died without dementia. General characteristics of individuals using angiotensin II-stimulating, angiotensin II-inhibiting, and combined angiotensin IIstimulating and negative antihypertensives (angiotensinmixed) are listed in table 1.

Mean age at baseline was $74.5( \pm 2.5)$ years. Compared to angiotensin II-inhibiting and angiotensin-mixed groups, respectively, the angiotensin II-stimulating group had the highest proportion of women (65 vs 46 and 53\%), highest mean diastolic BP ( 82.4 vs 81.4 and $80.7 \mathrm{~mm} \mathrm{Hg}$ ), and highest serum low-density lipoprotein ( $3.1 \mathrm{vs} 2.8$ and $2.8 \mathrm{mmol} / \mathrm{L}$ ). The angiotensin II-stimulating group had the lowest proportions with DM (20 vs 24 and 34\%), history of CVD (22 vs 52 and $47 \%$ ), and cholesterol-lowering medication (34 vs 52 and 54\%). The angiotensin II-inhibiting group had the lowest mean systolic BP (155.0 vs 156.6 and $157.9 \mathrm{~mm} \mathrm{Hg}$ ) and BMI
(27.8 vs 28.6 and $28.7 \mathrm{~kg} / \mathrm{m}^{2}$ ) compared to angiotensin IIstimulating and angiotensin-mixed groups, respectively.

Regarding antihypertensive use, angiotensin II-stimulating antihypertensive users less often used DiCCBs (30 vs $40 \%$ ) and more often ARBs (47 vs $25 \%$ ) compared to the angiotensinmixed group. Angiotensin II-inhibiting users more often used non-DiCCBs ( $12 \%$ vs $5 \%$ ) and less often BBs (64\% vs $75 \%$ ) compared to the angiotensin-mixed group. Angiotensin IIinhibiting antihypertensive users most often received additional treatment with loop diuretics ( $10.1 \%$ vs angiotensin IIstimulating: $2.4 \%$ and angiotensin-mixed: $7.2 \%$ ) and least often $\mathrm{K}$-sparing diuretics ( $4.5 \%$ vs angiotensin II-stimulating: $13.4 \%$ and angiotensin-mixed: $13.2 \%)$.

Dementia occurred in 5.6\% (27/480) of the angiotensin IIstimulating group, vs $6.9 \%(46 / 669)$ of the angiotensin-mixed and $8.2 \%(59 / 721)$ of the angiotensin II-inhibiting group. Results for the Cox regression analyses of incident dementia, mortality, and dementia/mortality for individuals using angiotensin IIstimulating and angiotensin-mixed antihypertensives compared to those using angiotensin II-inhibiting antihypertensives only are shown in table 2. Results for model 2 for the primary analyses are presented in the online supplement (tables e-1a through 1c), available from Dryad (doi.org/10.5061/dryad.hdr7squfd). The angiotensin II-stimulating group had a nonsignificant 33\% lower risk of dementia in model 1 (HR 0.67, 95\% confidence interval 
Table 3 Subgroup Analyses With Dementia as Outcome

\begin{tabular}{|c|c|c|c|c|c|c|c|c|c|c|}
\hline \multirow[b]{2}{*}{ Subgroup/AHD } & \multicolumn{5}{|l|}{ Model 1} & \multicolumn{5}{|l|}{ Model 3} \\
\hline & Events/exposed & HR & $95 \% \mathrm{Cl}$ & $p$ Value & $p$-int & Events/exposed & HR & $95 \% \mathrm{Cl}$ & $p$ Value & $p$-int \\
\hline \multicolumn{11}{|l|}{$\begin{array}{l}\text { No DM } \\
(n=92 / 1,376)\end{array}$} \\
\hline Ang- & $42 / 551$ & 1.00 & (ref) & & & $41 / 531$ & 1.00 & (ref) & & \\
\hline Ang+ & 21/381 & 0.70 & $(0.41-1.18)$ & 0.18 & 0.78 & $20 / 370$ & 0.64 & $(0.37-1.12)$ & 0.12 & 0.75 \\
\hline Ang士 & $29 / 444$ & 0.88 & $(0.55-1.41)$ & 0.59 & 0.57 & $26 / 416$ & 0.83 & $(0.5-1.35)$ & 0.45 & 0.65 \\
\hline \multicolumn{11}{|l|}{ DM $(n=40 / 494)$} \\
\hline Ang- & $17 / 170$ & & & & & $16 / 158$ & 1.00 & (ref) & & \\
\hline Ang+ & $6 / 99$ & 0.49 & $(0.19-1.25)$ & 0.14 & & $6 / 97$ & 0.50 & $(0.19-1.31)$ & 0.16 & \\
\hline Ang \pm & $17 / 225$ & 0.64 & $(0.32-1.25)$ & 0.19 & & $16 / 206$ & 0.73 & $(0.36-1.50)$ & 0.39 & \\
\hline \multicolumn{11}{|l|}{$\begin{array}{l}\text { No stroke } \\
(n=105 / 1,594)\end{array}$} \\
\hline Ang- & $49 / 626$ & 1.00 & (ref) & & & $48 / 604$ & 1.00 & (ref) & & \\
\hline Ang+ & $21 / 418$ & 0.60 & $(0.36-1.00)$ & 0.05 & 0.68 & $21 / 407$ & 0.57 & $(0.33-0.98)$ & 0.04 & 0.96 \\
\hline Ang \pm & $35 / 550$ & 0.80 & $(0.52-1.23)$ & 0.31 & 0.73 & $33 / 524$ & 0.75 & $(0.47-1.18)$ & 0.21 & 0.88 \\
\hline \multicolumn{11}{|l|}{$\begin{array}{l}\text { Stroke } \\
(n=24 / 251)\end{array}$} \\
\hline Ang- & $10 / 87$ & & & & & $9 / 85$ & 1.00 & (ref) & & \\
\hline Ang+ & $5 / 60$ & 0.70 & $(0.24-2.06)$ & 0.52 & & $5 / 60$ & 0.62 & $(0.20-1.95)$ & 0.41 & \\
\hline Ang \pm & 9/104 & 0.70 & $(0.29-1.74)$ & 0.45 & & $9 / 98$ & 0.91 & $(0.34-2.39)$ & 0.84 & \\
\hline \multicolumn{11}{|l|}{$\begin{array}{l}\text { No CVD } \\
(n=83 / 1,067)\end{array}$} \\
\hline Ang- & $31 / 340$ & 1.00 & (ref) & & & $31 / 328$ & 1.00 & (ref) & & \\
\hline Ang+ & $20 / 375$ & 0.53 & $(0.3-0.93)$ & 0.03 & 0.15 & $19 / 367$ & 0.50 & $(0.28-0.90)$ & 0.02 & 0.08 \\
\hline Ang \pm & $32 / 352$ & 0.9 & $(0.55-1.48)$ & 0.68 & 0.23 & $31 / 330$ & 0.95 & $(0.58-1.58)$ & 0.85 & 0.04 \\
\hline \multicolumn{11}{|l|}{$\begin{array}{l}\text { CVD } \\
(n=48 / 791)\end{array}$} \\
\hline Ang- & $27 / 375$ & 0.99 & $(0.43-2.27)$ & 0.97 & & $26 / 361$ & 1.00 & (ref) & & \\
\hline Ang+ & 7/102 & 0.65 & $(0.34-1.24)$ & 0.19 & & $7 / 100$ & 1.08 & $(0.46-2.53)$ & 0.87 & \\
\hline Ang士 & $14 / 314$ & 0.53 & $(0.30-0.93)$ & 0.03 & & $11 / 292$ & 0.55 & $(0.26-1.14)$ & 0.11 & \\
\hline \multicolumn{11}{|l|}{$\begin{array}{l}\text { SBP <147 mm Hg } \\
(n=46 / 624)\end{array}$} \\
\hline Ang- & $21 / 264$ & 1.00 & (ref) & & & $21 / 257$ & 1.00 & (ref) & & \\
\hline Ang+ & 9/151 & 0.69 & $(0.31-1.51)$ & 0.35 & 0.65 & $9 / 146$ & 0.73 & $(0.32-1.70)$ & 0.47 & 0.65 \\
\hline Ang士 & $16 / 209$ & 0.90 & $(0.47-1.74)$ & 0.76 & 0.47 & $15 / 196$ & 0.84 & $(0.42-1.68)$ & 0.62 & 0.57 \\
\hline \multicolumn{11}{|c|}{$\begin{array}{l}\text { SBP } 147-165 \mathrm{~mm} \mathrm{Hg} \\
(\mathrm{n}=47 / 634)\end{array}$} \\
\hline Ang- & $21 / 232$ & & & & & $19 / 218$ & 1.00 & (ref) & & \\
\hline Ang+ & $8 / 168$ & 0.49 & $(0.22-1.12)$ & 0.09 & & $8 / 164$ & 0.52 & $(0.22-1.25)$ & 0.15 & \\
\hline Ang \pm & $18 / 234$ & 0.85 & $(0.45-1.60)$ & 0.61 & & $16 / 215$ & 0.85 & $(0.43-1.67)$ & 0.64 & \\
\hline
\end{tabular}


Table 3 Subgroup Analyses With Dementia as Outcome (continued)

\begin{tabular}{|c|c|c|c|c|c|c|c|c|c|c|}
\hline \multirow[b]{2}{*}{ Subgroup/AHD } & \multicolumn{5}{|l|}{ Model 1} & \multicolumn{5}{|l|}{ Model 3} \\
\hline & Events/exposed & HR & $95 \% \mathrm{Cl}$ & $p$ Value & $p$-int & Events/exposed & HR & $95 \% \mathrm{Cl}$ & $p$ Value & $p$-int \\
\hline \multicolumn{11}{|c|}{$\begin{array}{l}\text { SBP } \geq 165 \mathrm{~mm} \mathrm{Hg} \\
(n=39 / 612)\end{array}$} \\
\hline Ang- & $17 / 225$ & & & & & $17 / 214$ & 1.00 & (ref) & & \\
\hline Ang+ & $10 / 161$ & 0.79 & $(0.36-1.74)$ & 0.56 & & $9 / 157$ & 0.66 & $(0.29-1.50)$ & 0.32 & \\
\hline Ang \pm & $12 / 226$ & 0.68 & $(0.33-1.43)$ & 0.32 & & $11 / 211$ & 0.68 & $(0.31-1.47)$ & 0.33 & \\
\hline
\end{tabular}

Abbreviations: AHD = antihypertensive drug; Ang+ = angiotensin II-stimulating medication; Ang- = angiotensin II-inhibiting medication; Ang \pm = both angiotensin II-stimulating and angiotensin II-inhibiting medication; $\mathrm{Cl}=$ confidence interval; $\mathrm{CVD}=$ cardiovascular disease; $\mathrm{DM}=$ diabetes mellitus; HR = hazard ratio; $($ ref $)=$ reference group.

Results of Cox proportional hazard analyses of incident dementia. Associations for Ang + and Ang \pm together in one model with Ang- as the reference category (i.e., HR 1.00). Age at time of event was used as time scale and age at baseline as time of study entry. Model 1: adjusted for sex; model 3: additionally adjusted for education, systolic blood pressure, history of DM, stroke, and CVD at baseline, body mass index, cholesterol medication use, estimated glomerular filtration rate, Mini-Mental State Examination score, and trial treatment arm. Results for model 2 are shown in table e-1b (doi.org/10.5061/dryad.hdr7sqvfd). $p$ Values for individual association, $p$-int $=p$ value for the interaction with the subgroup stratification ( 1 per angiotensin category for each subgroup analysis). $n=$ Total number of events/individuals per subgroup in model 1. Events/exposed = total number of events per individual in the angiotensin category per subgroup.

[CI] 0.42-1.06; $p=0.08)$. Adjusting for confounders, the angiotensin II-stimulating group had an approximately $40 \%$ lower risk of incident dementia in model 2 (HR $0.58,95 \%$ CI 0.36-0.93) and model 3 (HR 0.57, 95\% CI 0.35-0.93). This would correspond to an approximate absolute risk reduction (ARR) of 3.6\% (95\% CI 0.6-5.4). In all models, individuals in the angiotensin-mixed category had an approximately 20\% lower dementia risk, which was not statistically significant (model $3 \mathrm{HR}$ 0.77, 95\% CI 0.51-1.15; ARR 1.9\%, 95\% CI -1.2 to 4.0). There was no increased risk of mortality for individuals in the angiotensin II-stimulating group (model $3 \mathrm{HR} 0.86,95 \% \mathrm{CI} 0.64-1.16$; ARR $2.9 \%, 95 \% \mathrm{CI}-3.3$ to 7.5 ) and angiotensin-mixed group (model 3 HR 0.96, 95\% CI 0.75-1.23; ARR 0.8\%, 95\% CI -4.8 to 5.2 ) compared to individuals using angiotensin II-inhibiting antihypertensives only. Individuals in the angiotensin II-stimulating group had an estimated nonsignificant 20\% lower risk of dementia/mortality combined (HR 0.78, 95\% CI 0.60-1.02; ARR $6.0 \%, 95 \% \mathrm{CI}-0.5$ to 11.0$)$ compared to the angiotensin IIinhibiting group.

Results were consistent across subgroups stratified by history of DM, stroke, and systolic BP (table 3). There was an interaction with history of CVD in model 3 for both angiotensin II-stimulating $(p=0.08)$ and angiotensin-mixed $(p=0.04)$ groups. These suggested that the lower dementia risk for angiotensin II-stimulating vs angiotensin II-inhibiting antihypertensives was particularly evident in individuals without CVD (HR 0.50, 95\% CI $0.28-0.90$ vs HR 1.08 , 95\% CI 0.46-2.53). In contrast, for the angiotensin-mixed group, the $\mathrm{HR}$ was neutral in individuals without CVD (HR 0.95, 95\% CI 0.58-1.58) and markedly lower in those with CVD (HR 0.55, 95\% CI 0.26-1.14), though not significant. Results of the competing risk analyses with mortality (table e-2, doi.org/10. 5061/dryad.hdr7sqvfd) and dementia/mortality combined (table e-3, doi.org/10.5061/dryad.hdr7sqvfd) suggested that these interactions could not be explained by excess risks of mortality in subgroups based on CVD.
Results from sensitivity analyses including the nonthiazide diuretics in the angiotensin II-stimulating category were largely consistent for angiotensin II-stimulating antihypertensives (table e-4, doi.org/10.5061/dryad.hdr7sqvfd), with an approximately $40 \%$ lower risk of dementia (HR 0.59 , 95\% CI $0.36-0.95$ ) and no increased risk of mortality (HR 0.94, 95\% CI 0.70-1.27). Findings adjusting dementia outcome for the competing risk of death using the Fine-Gray model also corresponded to our main results (table e-5, doi.org/10.5061/dryad.hdr7sqvfd). The cumulative incidence plots corresponding to these analyses are depicted in figure e-1 (doi.org/10.5061/dryad.hdr7squfd). Sensitivity analysis adjusted for BP control at visit 2 gave similar HRs to the main analyses, but with wider CIs due to the lower number of participants for whom information was available (table e-6, doi.org/10. 5061/dryad.hdr7squfd). Sensitivity analyses adjusting for diastolic $\mathrm{BP}$, mean arterial BP, or pulse pressure instead of systolic BP gave similar results (table e-7, doi.org/10.5061/dryad.hdr7sqvfd). E-values for the point estimates in model 3 ranged from 1.25 to 2.91 (table e-8, doi.org/10.5061/dryad.hdr7sqvfd). For the HR of 0.57 (95\% CI 0.35-0.93) comparing angiotensin IIstimulating to angiotensin II-inhibiting antihypertensives with dementia as outcome, the HR E-value was 2.91 and the $95 \% \mathrm{CI}$ E-value 1.36. For the HR of 0.77 (95\% CI 0.51-1.15) comparing angiotensin II-stimulating to angiotensin II-inhibiting antihypertensives with dementia/mortality as outcome, the HRE-value was 1.92 and $95 \%$ CI E-value 1.00.

Exploratory analyses comparing individual antihypertensive subclasses showed no statistically significant associations with dementia risk (table 4). Looking at the point estimates, thiazide, DiCCBs, ARBs, non-DiCCBs, ACEIs, and loop diuretics all had HRs for dementia $\leq 1$ but only angiotensin IIstimulating (thiazides, DiCCBs, and ARBs) also had an $\mathrm{HR} \leq 1$ for mortality and dementia/mortality combined. To compare the predefined categorization of antihypertensive subclasses according to the angiotensin hypothesis to any random combination of antihypertensive subclasses, figure 3 depicts the HR 
Table 4 Hazard Ratios (HRs) for Individual Antihypertensive Types, Adjusted for Other Antihypertensive Drug (AHD) Use

\begin{tabular}{|c|c|c|c|c|c|c|c|c|}
\hline \multirow[b]{2}{*}{ Outcome/AHD } & \multicolumn{4}{|l|}{ Model 1} & \multicolumn{4}{|l|}{ Model 3} \\
\hline & Events/exposed $^{a}$ & HR & $95 \% \mathrm{Cl}$ & $p$ Value & Events/exposed $^{a}$ & HR & $95 \% \mathrm{Cl}$ & $p$ Value \\
\hline \multicolumn{9}{|c|}{ Dementia $(n=132 / 1,870)$} \\
\hline Thiazide & $41 / 563$ & 0.93 & $(0.62-1.38)$ & 0.71 & $39 / 538$ & 0.98 & $(0.65-1.49)$ & 0.94 \\
\hline DiCCB & $17 / 398$ & 0.58 & $(0.34-0.99)$ & 0.046 & $16 / 373$ & 0.58 & $(0.33-1.00)$ & 0.051 \\
\hline ARB & $20 / 389$ & 0.66 & $(0.38-1.16)$ & 0.15 & $18 / 370$ & 0.68 & $(0.38-1.22)$ & 0.20 \\
\hline Non-DiCCB & $9 / 116$ & 0.83 & $(0.37-1.86)$ & 0.66 & 7/108 & 0.61 & $(0.24-1.57)$ & 0.31 \\
\hline ACEI & $44 / 622$ & 1.00 & $(0.66-1.51)$ & 0.99 & $42 / 585$ & 0.98 & $(0.63-1.5)$ & 0.91 \\
\hline BB & $69 / 963$ & 0.91 & $(0.62-1.34)$ & 0.63 & $66 / 905$ & 1.09 & $(0.73-1.64)$ & 0.67 \\
\hline K-sparing & $12 / 188$ & 0.85 & $(0.47-1.54)$ & 0.59 & $11 / 177$ & 1.03 & $(0.55-1.94)$ & 0.92 \\
\hline Loop & $7 / 134$ & 0.80 & $(0.37-1.71)$ & 0.56 & $6 / 128$ & 0.78 & $(0.33-1.82)$ & 0.57 \\
\hline \multicolumn{9}{|c|}{ Mortality $(n=354 / 1,867)$} \\
\hline Thiazide & $99 / 563$ & 0.97 & $(0.76-1.23)$ & 0.78 & $95 / 538$ & 0.98 & $(0.76-1.26)$ & 0.87 \\
\hline DiCCB & $76 / 397$ & 1.03 & $(0.79-1.34)$ & 0.85 & $71 / 372$ & 0.94 & $(0.71-1.24)$ & 0.66 \\
\hline ARB & $68 / 388$ & 1.08 & $(0.81-1.45)$ & 0.60 & $65 / 369$ & 1.02 & $(0.75-1.38)$ & 0.91 \\
\hline Non-DiCCB & $29 / 116$ & 1.45 & $(0.95-2.22)$ & 0.09 & $28 / 108$ & 1.28 & $(0.82-2.00)$ & 0.28 \\
\hline ACEI & $140 / 622$ & 1.40 & $(1.11-1.76)$ & 0.004 & $132 / 585$ & 1.35 & $(1.06-1.72)$ & 0.02 \\
\hline BB & $188 / 960$ & 1.12 & $(0.89-1.40)$ & 0.33 & $176 / 902$ & 0.95 & $(0.75-1.21)$ & 0.68 \\
\hline K-sparing & $42 / 187$ & 1.35 & $(0.98-1.87)$ & 0.07 & $40 / 176$ & 1.23 & $(0.88-1.73)$ & 0.22 \\
\hline Loop & $47 / 134$ & 2.19 & $(1.61-2.98)$ & $<0.001$ & $46 / 128$ & 1.75 & $(1.25-2.45)$ & 0.001 \\
\hline \multicolumn{9}{|c|}{$\begin{array}{l}\text { Dementia/mortality } \\
(n=461 / 1,868)\end{array}$} \\
\hline Thiazide & $132 / 563$ & 0.95 & $(0.77-1.18)$ & 0.65 & $127 / 538$ & 0.99 & $(0.79-1.23)$ & 0.90 \\
\hline DiCCB & $90 / 397$ & 0.93 & $(0.73-1.19)$ & 0.58 & $84 / 372$ & 0.88 & $(0.69-1.14)$ & 0.34 \\
\hline ARB & $86 / 388$ & 0.99 & $(0.76-1.28)$ & 0.92 & $81 / 369$ & 0.95 & $(0.72-1.25)$ & 0.73 \\
\hline Non-DiCCB & $35 / 116$ & 1.22 & $(0.82-1.81)$ & 0.33 & $33 / 108$ & 1.07 & $(0.70-1.63)$ & 0.76 \\
\hline ACEI & $178 / 622$ & 1.32 & $(1.07-1.62)$ & 0.01 & $168 / 585$ & 1.29 & $(1.04-1.60)$ & 0.02 \\
\hline BB & $242 / 961$ & 1.06 & $(0.87-1.29)$ & 0.56 & $227 / 903$ & 0.98 & $(0.79-1.22)$ & 0.87 \\
\hline K-sparing & $51 / 187$ & 1.20 & $(0.90-1.61)$ & 0.22 & $48 / 176$ & 1.19 & $(0.87-1.62)$ & 0.27 \\
\hline Loop & $52 / 134$ & 1.82 & $(1.37-2.43)$ & $<0.001$ & $50 / 128$ & 1.58 & $(1.15-2.16)$ & 0.01 \\
\hline
\end{tabular}

Abbreviations: $\mathrm{ACEI}=$ angiotensin-converting enzyme inhibitor; $\mathrm{ARB}=$ angiotensin receptor blocker; $\mathrm{BB}=\beta$-blocker; $\mathrm{Cl}=$ confidence interval; $\mathrm{DiCCB}=$ dihydropyridine calcium channel blocker.

Results of Cox proportional hazard analyses of incident dementia/mortality as combined endpoint. HRs for each individual class in a separate model adjusted for concurrent use of other AHDs (yes/no). Age at time of event was used as time scale and age at baseline as time of study entry. Model 1: adjusted for sex; model 2: additionally adjusted for education, systolic blood pressure, and history of diabetes, stroke, and cardiovascular disease at baseline; model 3: additionally adjusted for body mass index, cholesterol medication use, estimated glomerular filtration rate, and trial treatment arm. Results for model 2 are shown in table e-1c (doi.org/10.5061/dryad.hdr7sqvfd). $\mathrm{n}=$ Total number of events/individuals in model 1 for each outcome. Events/exposed $=$ number of events/individuals using the listed AHD.

${ }^{a}$ Total numbers exposed may exceed total number of individuals in analyses because individuals can use multiple AHD types simultaneously. $p$ Values for individual association; $p$-int $=$ the $p$ value for the interaction with the subgroup stratification.

and $95 \%$ CIs for each possible combination of antihypertensive subclasses. From these, the predefined angiotensin IIstimulating antihypertensive classification (i.e., thiazides, DiCCBs, and ARBs) was among those observed to convey the lowest risk of dementia and dementia/mortality combined.

\section{Discussion}

In a population of community-dwelling older people, angiotensin II-stimulating antihypertensive use was associated with an approximately $40 \%$ lower risk of incident dementia 
Figure 3 Hazard Ratio (HR) and 95\% Confidence Interval (Cl) of Dementia, Mortality, and Dementia/Mortality as Combined Outcome for Each Possible Dichotomous Categorization of Antihypertensive Classes in the Study
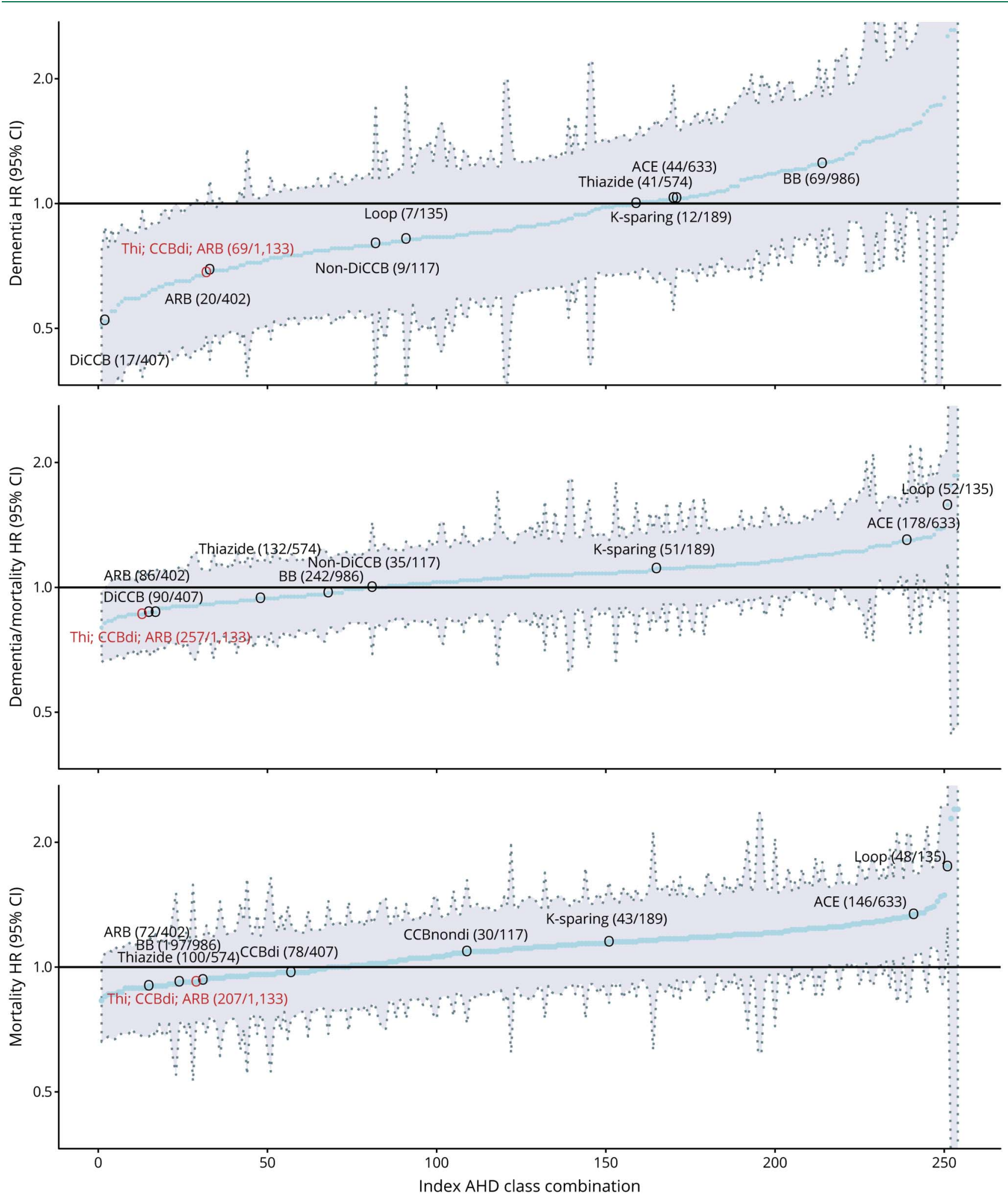

Depicted are the $\mathrm{HR}$ and $95 \% \mathrm{Cl}$ (y-axis) for each individual possible random combination of antihypertensive subclasses (thiazides, dihydropyridine calcium channel blockers [DiCCBs], non-DiCCBs, angiotensin receptor 1 blockers [ARBs], $\beta$-blockers [BBs], angiotensin-converting enzyme inhibitors [ACE], K-sparing and loop diuretics), in order of HR for the event from low to high on the x-axis. Each individual blue dot represents a possible combination. Only the HRs associated with the angiotensin II-stimulating medication (Ang+) combination hypothesized by this study (in red) and the individual antihypertensive classes on their own (gray) are marked. Within parentheses are the numbers of events followed by the number of individuals in the particular category at baseline. Note that the combined outcome of dementia/mortality is most useful for interpreting whether differences in dementia risk are due to differences in the competing risk of mortality. Models adjusted for systolic blood pressure, body mass index, cholesterol medication use, estimated glomerular filtration rate, education and history of diabetes, stroke, and cardiovascular disease at baseline. Index AHD = position of antihypertensive class combination from lowest to highest hazard ratio; Thi = thiazides ( \& thiazide-like). 
compared to angiotensin II-inhibiting antihypertensive use over 6.7 years of follow-up. This was not due to an increased risk of mortality. Results were independent of systolic BP, cardiovascular risk factors, and history of stroke or DM, and consistent throughout sensitivity analyses. There was a significant interaction suggesting the lower risk of dementia for angiotensin II-stimulating antihypertensive users was particularly evident in individuals without a history of CVD.

Several factors need consideration before interpreting these results. Conditions affecting dementia risk may also influence antihypertensive subclass prescriptions. Most notably: (1) ACEIs may be more commonly prescribed with DM; (2) BBs with heart failure, atrial fibrillation, and after myocardial infarction; (3) non-DiCCBs with atrial fibrillation; and (4) combinations of angiotensin II-stimulating and angiotensin II-inhibiting antihypertensives with greater hypertension severity. ${ }^{30}$ Subgroup analyses suggest these factors do not explain our overall results. The observed lower risks were evident in all sensitivity and subgroups analyses except in individuals with CVD. Nevertheless, we cannot exclude confounding by indication completely, since we do not know prescriber rationale for each particular antihypertensive regimen. However, associations for residual confounders would need to be strong to fully explain results. For our finding of a 44\% lower HR for angiotensin II-stimulating compared to angiotensin II-inhibiting antihypertensive users in model 3, the E-value would be 2.97, suggesting that an unmeasured confounder would need to have an HR of approximately 3 with both the exposure and outcome to fully explain away the association. This is $50 \%-100 \%$ larger than relative risks associated with known important noncongenital dementia risk factors. ${ }^{1,34}$ Second, we used antihypertensive data from the PreDIVA baseline without accounting for adherence. Furthermore, we do not know when antihypertensive treatment was initiated. Our analyses therefore assume that treatment exposure did not substantially differ between subclasses (or did not influence risk differences). Differences in adherence by subclasses may influence our results, but evidence does not suggest adherence is clearly better or worse for angiotensin II-stimulating compared to angiotensin II-inhibiting drug classes; dosing frequency and number of concurrent medications seem more important factors for adherence. ${ }^{35-38} \mathrm{How}$ treatment duration and exposure affects the observed risks requires future study. Third, dementia was operationalized as an independent committee-adjudicated clinical diagnosis, confirmed after 1 year additional follow-up. This corroborated diagnostic validity and clinical generalizability but may have lowered sensitivity, leading to missed cases. These misclassifications are likely unrelated to antihypertensive subclass use (nondifferential), causing bias towards the null, leading to underestimated associations. Fourth, although we controlled for history of stroke, this definition included TIA, which is very different both clinically and prognostically. This is expected to have limited effect on our overall results, but it is important to consider when interpreting the results of our stroke subgroup analyses. Fourth, although overall analyses were sufficiently powered, some analyses in small subgroups lacked power, especially in model 3. The observed interactions (e.g., with CVD) therefore require cautious interpretation. Fourth, although chance is an unlikely explanation for our main findings, because we tested a prespecified hypothesis with ample power, the subanalyses assessing HRs for each possible subclass categorization are sensitive to type II error. However, these were exploratory analyses to compare our predefined antihypertensive categorization to any random alternative. Finally, using RCT cohort data could have limited generalizability. This is unlikely, however. PreDIVA had a pragmatic, population-based design, and the trial population was comparable to Dutch national population cohort data. ${ }^{26,39}$ Moreover, the trial intervention did not recommend particular antihypertensive types, had no effect on dementia incidence, and sensitivity analysis adjusting for the intervention gave similar results. ${ }^{26,40}$

Overall, our results largely support the angiotensin hypothesis that certain antihypertensive subclasses convey a reduced risk of dementia compared to others, based on their RAS activity, independent of BP effects. Hypothetically, activity at the AT2 and AT4 receptors reduces dementia incidence by protecting the brain from ischemic damage (particularly AT2) $)^{16,21,22}$ and stimulating memory function (through AT4). ${ }^{23,24}$ ARBs, thiazide diuretics, and DiCCBs are generally thought to upregulate angiotensin II production, thereby stimulating activity at the AT2 and AT4 receptors. ${ }^{18,27,28}$ ACEIs, BBs, and non-DiCCBs are generally thought to downregulate angiotensin II production, thereby diminishing the positive activity at the AT2 and AT4 receptors. ${ }^{18,29}$ Furthermore, angiotensin-converting enzyme (ACE) reportedly degrades $A \beta$ in the brain, a protein widely considered to be involved in the pathophysiology of Alzheimer disease. ${ }^{16,25}$ ACEIs may reduce this degradation by inhibiting ACE activity, thus facilitating $A \beta$ plaque accumulation. ${ }^{18}$ ARBs selectively inhibit angiotensin II at AT1 without inhibiting ACE, thus leaving $A \beta$ degradation intact. ${ }^{18}$ Moreover, by selectively inhibiting angiotensin II activity at the AT1 receptor, ARBs stimulate activity at the AT2 and AT4 receptors. ${ }^{18}$ Taken together, antihypertensives that increase activity at AT2 and AT4 (angiotensin II-stimulating antihypertensives) are hypothesized to have greater brain protective effects than those that decrease activity at the same receptors (angiotensin II-inhibiting antihypertensives). Several different antihypertensive classes have previously been associated with reduced risks of incident dementia. ${ }^{6-12,15}$ The angiotensin hypothesis provides an overarching pathophysiologic framework to better understand the heterogeneous findings regarding antihypertensive use and dementia risk. ${ }^{16,17}$ Because a number of methodologic biases may influence these associations, the inconsistencies in previous studies' results are not surprising. ${ }^{6-12,15}$

Our analyses suggest that the difference between angiotensin II-stimulating and angiotensin II-inhibiting antihypertensives might be driven by DiCCBs and ARBs rather than thiazides, although all 3 conveyed lower dementia risks without 
increased mortality. DiCCBs were associated with the lowest dementia risk. This may reflect protective effects of DiCCB beyond angiotensin II stimulation (e.g., stimulating angiogenesis), ${ }^{6,15}$ or chance/bias from the study's relatively small number of DiCCB users, high number of comparisons, and observational design. Previous studies have found both lower ${ }^{7,9,41}$ and higher ${ }^{42,43}$ dementia risks for calcium channel blockers (CCBs) compared to ARBs and also lower ${ }^{42-44}$ and higher ${ }^{7,9,41,45}$ dementia risks for CCBs compared to diuretics. However, none of these were significant in direct comparison. Substantial differences in methodology may underlie these heterogeneous results. In our study, as hypothesized, ACEIs were among the subclasses conveying the highest dementia risk. This effect was not moderated by a history of DM, suggesting that confounding by indication is unlikely to be driving this association. ACEIs have been associated with higher dementia risks compared to other antihypertensive subclasses in clinical studies. ${ }^{6-12,15}$ This is supported by findings that $\mathrm{ACE}$ facilitates $\mathrm{A} \beta$ degradation. ${ }^{16,17}$ The higher risk associated with $\mathrm{BBs}$ also corresponds to previous findings. ${ }^{6-12,15}$ The risks associated with K-sparing and loop diuretics are difficult to interpret because these are almost always prescribed as adjunct medications for comorbidities such as heart or renal failure and electrolyte disorders. ${ }^{30}$

Our findings warrant replication in other longitudinal cohorts. Being observational, they cannot establish definitive causal relationships. Causality could be strengthened by combining clinical observations with dementia-associated neuropathology. The few data available suggest that cognitively intact individuals on ARBs have slower atrophy rates and less cerebral A $\beta$ deposition than those on ACEIs. ${ }^{46,47}$ The angiotensin hypothesis ideally requires RCT testing. Trials comparing antihypertensive subclasses with dementia as primary outcome are challenging, requiring many participants and long follow-up. ${ }^{48}$ Designing intervention and control conditions is also problematic, since withholding antihypertensive treatment is unethical, several subclasses potentially reduce dementia risks, and guidelines recommend combining subclasses, which decreases potential for between-type comparisons. The angiotensin hypothesis could help address these issues, suggesting 3 different antihypertensive subclasses available for the intervention (ARBs, DiCCBs, thiazides), and all others for the control group. This may greatly facilitate trial design and improve power. Lacking RCT data, there is an imperative need to robustly study candidate brain protectants, including antihypertensives, from longitudinal observational studies using clinical dementia outcome measures. Our results suggest future treatment of hypertension could include a compelling indication for certain antihypertensive subclasses. This would be easy and affordable to implement in clinical practice, because the antihypertensives studied are common first-line antihypertensive treatments available in generic forms. ${ }^{30}$ In a recent survey among antihypertensive users, most (>90\%) reported to be willing to take a specific subclass as early as in midlife, if the medication was shown to prevent or delay dementia. ${ }^{49}$ Given hypertension's high prevalence, even modest differences in antihypertensive effects on the aging brain would have substantial implications for public health.

This study found that individuals using angiotensin IIstimulating antihypertensives had approximately $40 \%$ lower dementia rates compared to those using angiotensin IIinhibiting antihypertensives. This association was not due to increased mortality and was independent of cardiovascular risk factors and comorbidity, but it may be specific for individuals without CVD. Although we tested a prespecified hypothesis, this study is the first to evaluate these associations, and replication is necessary to allow definitive conclusions. If replicated, the beneficial effects associated with angiotensin II-stimulating antihypertensives could have major influence on clinical practice, providing a treatment strategy that is easy and inexpensive to implement on a large scale and could markedly reduce dementia risk on a population level.

\section{Study Funding}

The PreDIVA trial was funded by the Dutch Ministry of Health, Welfare and Sport (grant number 50-50110-98-020), the Dutch Innovation Fund of Collaborative Health Insurances (grant number 05-234), and the Netherlands Organisation for Health Research and Development (grant number 62000015). The current research is supported by VIDI grant 91718303 to E. Richard from the Dutch Research Council (NWO) Health Research and Development (ZonMW) VIDI programme. Z.A. Marcum was supported by an Agency for Healthcare Research \& Quality grant (K12HS022982) and the National Institute on Aging of the NIH (K76AG059929). The content is solely the responsibility of the authors and does not necessarily represent the official views of the NIH. The PreDIVA trial was registered with ISRCTN, number ISRCTN29711771.

\section{Disclosure}

The authors report no disclosures relevant to the manuscript. Go to Neurology.org/N for full disclosures.

\section{Publication History}

Received by Neurology February 18, 2020. Accepted in final form August 12, 2020.

\section{Appendix Authors}

\begin{tabular}{lll}
\hline Name & Location & Contribution \\
\hline $\begin{array}{l}\text { Jan Willem } \\
\text { Pan Dalen, }\end{array}$ & $\begin{array}{l}\text { Amsterdam UMC, } \\
\text { University of Amsterdam, } \\
\text { Amsterdam \& Donders } \\
\text { Institute for Brain, } \\
\text { Behaviour and Cognition, } \\
\text { Radboud University } \\
\text { Medical Centre, Nijmegen, } \\
\text { the Netherlands }\end{array}$ & $\begin{array}{l}\text { Design and } \\
\text { conceptualization of study, } \\
\text { data analysis and } \\
\text { interpretation, drafted the } \\
\text { manuscript for intellectual } \\
\text { content, access to all the } \\
\text { data and responsibility for } \\
\text { the data, accuracy of data } \\
\text { analysis and conduct of the } \\
\text { research }\end{array}$ \\
& & \\
\end{tabular}


Appendix (continued)

\begin{tabular}{ll}
\hline Name & Location \\
\hline Zachary A. & University of Washington, \\
Marcum, & School of Pharmacy, \\
PharmD, & Seattle \\
PhD &
\end{tabular}

Contribution

Design and

conceptualization of study, conceptualization of antihypertensive angiotensin hypothesis, data and interpretation, drafted the manuscript for intellectual content

\begin{tabular}{ll}
\hline Shelly L. & University of Washington, \\
Gray, & School of Pharmacy, \\
PharmD, MS & Seattle
\end{tabular}

Conceptualization of antihypertensive angiotensin hypothesis, data interpretation, revision of manuscript for intellectual content

\begin{tabular}{ll}
\hline Douglas & University of Washington, \\
Barthold, & School of Pharmacy, \\
PhD & Seattle
\end{tabular}

Conceptualization of antihypertensive angiotensin hypothesis, data interpretation, revision of manuscript for intellectual content

\begin{tabular}{ll}
\hline Eric P. Moll & Amsterdam UMC, \\
van & University of Amsterdam, \\
Charante, & the Netherlands \\
MD, PhD &
\end{tabular}

Major role in acquisition of the data, data interpretation, revision of manuscript for intellectual content

\begin{tabular}{ll}
\hline Willem A. & Amsterdam UMC, \\
van Gool, & University of Amsterdam, \\
MD, PhD & the Netherlands
\end{tabular}

Major role in acquisition of the data, data interpretation, revision of manuscript for intellectual content

\begin{tabular}{ll}
\hline Paul K. & University of Washington, \\
Crane, MD, & School of Medicine, Seattle \\
MPH &
\end{tabular}

\section{Design and}

conceptualization of study, conceptualization of antihypertensive angiotensin hypothesis, data interpretation, revision of manuscript for intellectual content

\begin{tabular}{ll}
\hline Eric B. & Kaiser Permanente \\
Larson, MD, & Washington Health \\
MPH & Research Institute, Seattle
\end{tabular}

Design and

conceptualization of study, conceptualization of antihypertensive angiotensin hypothesis, revision of manuscript for intellectual content

Edo Richard, Donders Institute for Brain, MD, PhD Behaviour and Cognition, Radboud University Medical Centre, Nijmegen \& Amsterdam UMC, University of Amsterdam, the Netherlands
7. Tan ECK, Qiu C, Liang Y, et al. Antihypertensive medication regimen intensity and incident dementia in an older population. J Am Med Dir Assoc 2018;19:577-583.

8. van Middelaar T, van Vught LA, van Charante EPM, et al. Lower dementia risk with different classes of antihypertensive medication in older patients. J Hypertens 2017; 35:2095-2101.

9. Tully PJ, Dartigues JF, Debette S, Helmer C, Artero S, Tzourio C. Dementia risk with antihypertensive use and blood pressure variability: a cohort study. Neurology 2016; 87:601-608.

10. Hussain S, Singh A, Rahman SO, Habib A, Najmi AK. Calcium channel blocker use reduces incident dementia risk in elderly hypertensive patients: a meta-analysis of prospective studies. Neurosci Lett 2018;671:120-127.

11. Tully PJ, Hanon O, Cosh S, Tzourio C. Diuretic antihypertensive drugs and incident dementia risk: a systematic review, meta-analysis and meta-regression of prospective studies. J Hypertens 2016;34:1027-1035.

12. Zhuang S, Wang HF, Li J, Wang HY, Wang X, Xing CM. Renin-angiotensin system blockade use and risks of cognitive decline and dementia: a meta-analysis. Neurosci Lett 2016;624:53-61.

13. Novotny M, Klimova B, Valis M. Nitrendipine and dementia: forgotten positive facts? Front Aging Neurosci 2018;10:418.

14. Barthold D, Joyce G, Wharton W, Kehoe P, Zissimopoulos J. The association of multiple anti-hypertensive medication classes with Alzheimer's disease incidence across sex, race, and ethnicity. PLoS One 2018;13:e0206705.

15. Peters R, Schuchman M, Peters J, Carlson MC, Yasar S. Relationship between antihypertensive medications and cognitive impairment: Part II. Review of physiology and animal studies. Curr Hypertens Rep 2016;18:66.

16. Kehoe PG. The coming of age of the angiotensin hypothesis in Alzheimer's disease: progress toward disease prevention and treatment? J Alzheimers Dis 2018;62: 1443-1466.

17. Petek B, Villa-Lopez M, Loera-Valencia R, et al. Connecting the brain cholesterol and renin-angiotensin systems: potential role of statins and RAS-modifying medications in dementia. J Intern Med 2018;284:620-642.

18. Brown MJ. Renin: friend or foe? Heart 2007;93:1026-1033.

19. Kaschina E, Namsolleck P, Unger T. AT2 receptors in cardiovascular and renal diseases. Pharmacol Res 2017;125:39-47.

20. Forrester SJ, Booz GW, Sigmund CD, et al. Angiotensin II signal transduction: an update on mechanisms of physiology and pathophysiology. Physiol Rev 2018;98: $1627-1738$.

21. Saavedra JM, Benicky J, Zhou J. Mechanisms of the anti-ischemic effect of angiotensin II AT1 receptor antagonists in the brain. Cell Mol Neurobiol 2006;26:1099-1111.

22. Horiuchi M, Mogi M. Role of angiotensin II receptor subtype activation in cognitive function and ischaemic brain damage. Br J Pharmacol 2011;163:1122-1130.

23. Ho JK, Nation DA. Cognitive benefits of angiotensin IV and angiotensin-(1-7): a systematic review of experimental studies. Neurosci Biobehav Rev 2018;92:209-225.

24. Hamel E, Royea J, Ongali B, Tong XK. Neurovascular and cognitive failure in Alzheimer's disease: benefits of cardiovascular therapy. Cell Mol Neurobiol 2016;36: 219-232.

25. Baranello RJ, Bharani KL, Padmaraju V, et al. Amyloid-beta protein clearance and degradation $(\mathrm{ABCD})$ pathways and their role in Alzheimer's disease. Curr Alzheimer Res 2015;12:32-46.

26. Moll van Charante EP, Richard E, Eurelings LS, et al. Effectiveness of a 6-year multidomain vascular care intervention to prevent dementia (PreDIVA): a clusterrandomised controlled trial. Lancet 2016;388:797-805.

27. Duarte JD, Cooper-DeHoff RM. Mechanisms for blood pressure lowering and metabolic effects of thiazide and thiazide-like diuretics. Expert Rev Cardiovasc Ther 2010; 8:793-802.

28. Ellison DH, Felker GM. Diuretic treatment in heart failure: from physiology to clinical trials. N Engl J Med 2017;377:1964.

29. Bauer JH, Sunderrajan S, Reams G. Effects of calcium entry blockers on reninangiotensin-aldosterone system, renal function and hemodynamics, salt and water excretion and body fluid composition. Am J Cardiol 1985;56:62 H-67H.

30. Whelton PK, Carey RM, Aronow WS, et al. 2017 ACC/AHA/AAPA/ABC/ACPM/AGS/ APhA/ASH/ASPC/NMA/PCNA Guideline for the prevention, detection, evaluation, and management of high blood pressure in adults. J Am Coll Cardiol 2018;71:e127-e248.

31. Wolkewitz M, Cooper BS, Bonten MJM, Barnett AG, Schumacher M. Interpreting and comparing risks in the presence of competing events. BMJ 2014;349:g5060.

32. Haneuse S, Vanderweele TJ, Arterburn D. Using the E-value to assess the potential effect of unmeasured confounding in observational studies. JAMA 2019;321:602-603.

33. Mathur MB, Ding P, Riddell CA, VanderWeele TJ. Web site and R package for computing E-values. Epidemiology 2018;29:e45-e47.

34. Norton S, Matthews FE, Barnes DE, Yaffe K, Brayne C. Potential for primary prevention of Alzheimer's disease: an analysis of population-based data. Lancet Neurol 2014;13:788-794.

35. Moise N, Schwartz J, Bring R, Shimbo D, Kronish IM. Antihypertensive drug class and adherence: an electronic monitoring study. Am J Hypertens 2015;28:717-721.

36. Schulz M, Krueger K, Schuessel K, et al. Medication adherence and persistence according to different antihypertensive drug classes: a retrospective cohort study of 255,500 patients. Int J Cardiol 2016;220:668-676.

37. Kurdi AI, Chen LC, Elliott RA. Exploring factors associated with patients' adherence to antihypertensive drugs among people with primary hypertension in the United Kingdom. J Hypertens 2017;35:1881-1890.

38. Kronish IM, Woodward M, Sergie Z, Ogedegbe G, Falzon L, Mann DM. Metaanalysis: impact of drug class on adherence to antihypertensives. Circulation 2011, 123:1611-1621. 
39. Ligthart SA, Richard E, van Gool WA, et al. Cardiovascular risk management in community-dwelling elderly: opportunities for prevention. Eur J Prev Cardiol 2012; 19:1365-1372.

40. Van Middelaar T, Van Vught LA, Van Charante EPM, et al. Lower dementia risk with different classes of antihypertensive medication in older patients. J Hypertens 2017;35.

41. Hwang D, Kim S, Choi H, et al. Calcium-channel blockers and dementia risk in older adults: National Health Insurance Service: Senior Cohort (2002-2013). Circ J 2016; 80:2336-2342.

42. Murray MD, Hendrie HC, Lane KA, et al. Antihypertensive medication and dementia risk in older adult African Americans with hypertension: a prospective cohort study. J Gen Intern Med 2018;33:455-462.

43. Yasar S, Xia J, Yao W, et al. Antihypertensive drugs decrease risk of Alzheimer disease ginkgo evaluation of memory study. Neurology 2013;81:896-903.

44. Rastas S, Pirttilä T, Mattila K, et al. Vascular risk factors and dementia in the general population aged $>85$ years: prospective population-based study. Neurobiol Aging 2010;31:1-7.
45. Gelber RP, Ross GW, Petrovitch H, Masaki KH, Launer LJ, White LR. Antihypertensive medication use and risk of cognitive impairment the Honolulu-Asia Aging Study. Neurology 2013;81:888-895.

46. Moran C, Xie K, Poh S, et al. Observational study of brain atrophy and cognitive decline comparing a sample of community-dwelling people taking angiotensin converting enzyme inhibitors and angiotensin receptor blockers over time. J Alzheimers Dis 2019;68:1479-1488.

47. Hajjar I, Brown L, Mack WJ, Chui H. Impact of angiotensin receptor blockers on Alzheimer disease neuropathology in a large brain autopsy series. Arch Neurol 2012; 69:1632-1638.

48. Richard E, Andrieu S, Solomon A, et al. Methodological challenges in designing dementia prevention trials: the European Dementia Prevention Initiative (EDPI) J Neurol Sci 2012;322:64-70.

49. Marcum ZA, Hohl SD, Gray SL, Barthold D, Crane PK, Larson EB. Patient perceptions of antihypertensive use as a dementia prevention strategy: a mixed-method analysis of a web-based survey. J Alzheimers Dis 2019;68:523-529. 


\section{Neurology}

\section{Association of Angiotensin II-Stimulating Antihypertensive Use and Dementia Risk: Post Hoc Analysis of the PreDIVA Trial}

Jan Willem van Dalen, Zachary A. Marcum, Shelly L. Gray, et al.

Neurology 2021;96;e67-e80 Published Online before print November 5, 2020

DOI 10.1212/WNL.0000000000010996

This information is current as of November 5, 2020

\section{Updated Information \&} Services

References

Subspecialty Collections

Permissions \& Licensing

Reprints including high resolution figures, can be found at: http://n.neurology.org/content/96/1/e67.full

This article cites 48 articles, 7 of which you can access for free at: http://n.neurology.org/content/96/1/e67.full\#ref-list-1

This article, along with others on similar topics, appears in the following collection(s):

All Cognitive Disorders/Dementia

http://n.neurology.org/cgi/collection/all_cognitive_disorders_dementia Cohort studies

http://n.neurology.org/cgi/collection/cohort_studies

Risk factors in epidemiology

http://n.neurology.org/cgi/collection/risk_factors_in_epidemiology

Information about reproducing this article in parts (figures,tables) or in its entirety can be found online at:

http://www.neurology.org/about/about_the_journal\#permissions

Information about ordering reprints can be found online:

http://n.neurology.org/subscribers/advertise

Neurology ${ }^{\circledR}$ is the official journal of the American Academy of Neurology. Published continuously since 1951, it is now a weekly with 48 issues per year. Copyright Copyright ( 2020 The Author(s). Published by Wolters Kluwer Health, Inc. on behalf of the American Academy of Neurology.. All rights reserved. Print ISSN: 0028-3878. Online ISSN: 1526-632X.

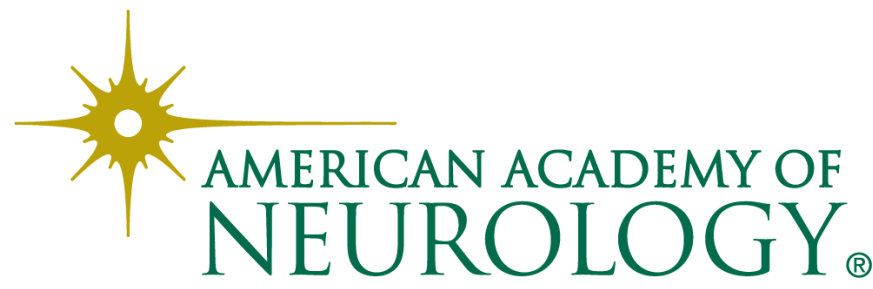

